\title{
Histology of White Pine Blister Rust in Needles of Resistant and Susceptible Eastern White Pine
}

Joel A. Jurgens and Robert A. Blanchette, Department of Plant Pathology, University of Minnesota, 495 Borlaug Hall, 1991 Upper Buford Circle, St. Paul 55108-6030; Paul J. Zambino, USDA Forest Service, Rocky Mountain Research Station, 1221 South Main Street, Moscow, Idaho 83843; and Andrew David, University of Minnesota, North Central Research and Outreach Center, Grand Rapids 55744

\begin{abstract}
Jurgens, J. A., Blanchette, R. A., Zambino, P. J., and David, A. 2003. Histology of white pine blister rust in needles of resistant and susceptible eastern white pine. Plant Dis. 87:1026-1030.

White pine blister rust, Cronartium ribicola, has plagued the forests of North America for almost a century. Over past decades, eastern white pine (Pinus strobus) that appear to tolerate the disease have been selected and incorporated into breeding programs. Seeds from $P$. strobus with putative resistance were collected from Oconto River Seed Orchard, Nicolet National Forest, WI. Seedlings were grown for 5 months and artificially inoculated with basidiospores of $C$. ribicola in two replicated greenhouse experiments. Needles from infected seedlings were fixed, sectioned, and stained with a variety of histological reagents, and rate of mortality for the remaining seedlings was monitored. The most susceptible families suffered $50 \%$ mortality in approximately half the time of the more resistant families. Extensive inter- and intracellular hyphae were observed in needles from seedlings of susceptible families, whereas hyphal proliferation was restricted in needles of resistant seedlings. Needles from resistant families had pronounced responses to infection. Phenolics, observed with phloroglucinol-HCl staining, were deposited around infection sites where dense mycelial masses were present. Abnormal host cell growth and rapid cell death in the immediate area of infection were also observed in some eastern white pine families.
\end{abstract}

Additional keywords: five-needle pines, host response

The introduction of white pine blister rust, caused by Cronartium ribicola J.C. Fisch. ex Rabenh., to North America approximately 100 years ago has devastated populations of native five-needled pines (Pinus subgenus strobus) in many regions (17). The histopathology of this disease in susceptible pine tissues has been well documented $(2,3,16,25)$. Histological investigations have also been conducted on trees with resistance expressed in needle or stem tissue. For example, major gene resistance (MGR) in sugar pine (Pinus lambertiana) $(12,14)$ and western white pine (P. monticola) (15) was characterized by a hypersensitive reaction in needles at the site of initial colonization. The reaction was visible macroscopically as a tan or brown "fleck" spot, but was characterized histologically by degeneration of both host and fungal cells and deposition of host defense compounds. MGR has also been detected in limber pine ( $P$. flexilis) and southwestern white pine ( $P$. strobiformis, sometimes considered a subspe-

Corresponding author: J. A. Jurgens

E-mail: jurgens@umn.edu

Accepted for publication 2 May 2003.

Publication no. D-2003-0708-01R

(C) 2003 The American Phytopathological Society cies of $P$. flexilis), but not as yet in $P$. strobus (13).

Mechanisms that appear to limit infection of needles through stomata prior to host colonization have been investigated in eastern white pine ( $P$. strobus) and western white pine. Patton and others $(19,20,22)$ suggested that in eastern white pine, wax plugs in stomata and the inability of $C$. ribicola to pass guard cells may be mechanical barriers that account for the "reduced needle spot frequency". Recent work by Woo et al. (28) indicated that reduced needle spot frequency in western white pine was not generally correlated with the morphology of needle surfaces and stomata, although stomata in one resistant family were significantly smaller than in susceptible families. Patton (18) and Patton and Johnson (20) also documented that $C$. ribicola failed to colonize eastern white pine needle tissue of one "highly resistant" grafted selection after artificial inoculation.

Degree and expression of resistance among seedlings within resistant families of eastern white pine appear to vary greatly. Expression ranges from small needle spots, spots that never produce stem cankers, few stem lesions, and slow canker growth and extended delay or lack of aeciospore production $(6,23,24)$. Struckmeyer and Riker (25) observed that the formation of wound periderm in phloem of resistant eastern white pines served as a barrier to "cork out" the fungus, thus preventing it from progressing further into healthy tissue.

Because of the various expressions of resistance, it is useful to study resistance mechanisms in needle, branch, and stem tissues of pine. In this investigation, histological techniques are used to examine colonization by the fungus and host reactions in secondary needles of resistant and susceptible seedlings of $P$. strobus. Openpollinated, half-sib seedlings from trees selected as resistant in the field and studied for resistance in progeny tests decades prior to this study $(21,24)$, as well as susceptible seedlings, were artificially inoculated with $C$. ribicola, the rate of mortality monitored, and histological observations made of host-parasite interactions.

\section{MATERIALS AND METHODS}

Five sources of open-pollinated, half-sib progeny were obtained from grafted clones of field selections maintained at the U.S. Forest Service, Oconto River Seed Orchard (ORSO), White Lake, WI. Selections P 30, P 312, and P 327 were chosen based on evidence of heritable resistance in a historic selection program. The "P" prefix indicates trees from natural forests that were examined and selected by Professor Emeritus Robert Patton, University of Wisconsin, and were free of disease but growing in high rust zones. Selection P 30 was collected in Dunn County, WI; P 312 and P 327 were collected in St. Louis County, MN. P 30 has also been shown to be resistant in plantations in coastal British Columbia (8).

Open pollinated, half-sib families from selections H 111 and WI 352 were used as susceptible controls. Foresters in Langlade County, WI, in 1966 and in Hiawatha County, WI, in 1965 made the original collections of WI 352 and H 111. As with the resistant selections, these trees had appeared to be relatively canker-free in areas having a high occurrence of blister rust, but subsequent seedling progeny tests at ORSO indicated a very high incidence of infection. H 111 has also shown high levels of infection at coastal British Columbia plantations (8). The susceptibility of H 111 and WI 352 was further indicated by the rapid onset of mortality compared with resistant families when seedlings bearing only primary needles were inocu- 
lated and monitored in greenhouse studies (29).

Seed was surface-sterilized in $1 \%$ bleach for $30 \mathrm{~s}$ and soaked in running water for 24 $\mathrm{h}$ before being stratified at $4^{\circ} \mathrm{C}$ for 60 days prior to planting. Seeds were planted in 66 $\mathrm{cm}^{3}$ (4 cu in) containers (Ray Leach Conetainers, Stuewe \& Sons, Corvallis, OR) in a quick-draining mixture of peat and vermiculite (RediEarth, Scotts, Marysville, $\mathrm{OH})$ into which $300 \mathrm{~g}$ of Osmocote-Plus 9month release 15-9-12 fertilizer (Scotts) had been incorporated per 85-liter bag. Seedlings were grown in the greenhouse under metal halide lights with a 16-h photoperiod. Supplemental fertilizer (a soil drench of $14.7 \mathrm{ml}$ of Miracid [Scotts] per 3.79 liters of water) was applied 1 week after emergence and once a month after inoculation. Similar nutrient-rich conditions in sugar pine provided rapid growth conducive to obtaining abundant rust infections (11).

Two experiments utilized seedlings that had been grown and inoculated at different times. For each of the experiments, 60 seedlings from each selection were inoculated 5 months after germination, as secondary needles were abundant by this time and needle infections can be readily obtained at this age for both susceptible and resistant families of eastern white pine (21). Seedlings were placed in an environmentally controlled incubation chamber with a relative humidity (RH) of $100 \%, 12$ $\mathrm{h}$ photoperiod, and temperature of $18^{\circ} \mathrm{C}$ the day before inoculation. For each experiment, the strain of $C$. ribicola used was derived from a single aeciospore (WI4.1B) obtained near Wabeno, WI. Telia were produced in a growth chamber with a 12-h photoperiod at $20^{\circ} \mathrm{C} / 15^{\circ} \mathrm{C}$ on the susceptible "Heimberger clone" of Ribes nigrum (19). Leaves were harvested, soaked overnight in distilled water at $4^{\circ} \mathrm{C}$, then suspended above the seedlings in an unlit incubation chamber until a density of 6,000 basidiospores per $\mathrm{cm}^{2}$ was cast across the six blocked replications in each experiment. Ribes leaves were then removed and the seedlings incubated for an additional 72 $\mathrm{h}$ at $18^{\circ} \mathrm{C}, 100 \% \mathrm{RH}$, with 12 -h photoperiods of diffuse light. This exceeded the 52-h estimated minimum time needed for basidiospore germination and infection (26), while avoiding stress to the seedlings. Upon removal from the incubation chamber, seedlings were placed in the greenhouse under the same conditions used prior to inoculation.

Secondary needles with infection spots were collected from seedlings 7 weeks after inoculation and prepared for histological examination. Needle tissues were fixed in formalin-acetic acid-ethyl alcohol (FAA), dehydrated in a tertiary-butyl alcohol series, and embedded in paraffin. Longitudinal serial sections were cut at 12 to $14 \mu \mathrm{m}$ and stained with the periodic acidSchiff technique to examine hyphae in needles (4) or phloroglucinol-HCl for identification of phenolic compounds (9).

For each experiment, seedling mortality was monitored every 2 weeks after inoculation. Significant differences $(P=0.05)$ among families in time (weeks) to reach 30,50 , and $70 \%$ mortality were based on Kaplin-Meier analysis (10) performed using Statistix ${ }^{\circledR} 7$ software (Analytical Software, Tallahassee, FL).

\section{RESULTS}

When comparing seedlings in experiment 1 , susceptible selections $\mathrm{H} 111$ and WI 352 reached $70 \%$ mortality 120 and 116 weeks earlier, respectively, than P 327 , the most resistant selection. In experiment 2, these same susceptible selections reached $70 \%$ mortality 28 and 19 weeks earlier than the more resistant selections $\mathrm{P}$ 30 and P 327 (Table 1). Families P 30, P 312 , and $P 327$ each showed longer average survival when compared with families H 111 and WI 352. In experiment 1, H 111 and WI 352 showed significant differences $(P=0.05)$ from families $\mathrm{P} 30, \mathrm{P} 312$, and $\mathrm{P}$ 327 in time to 30,50 , and $70 \%$ mortality according to Kaplin Meier analysis (Table 1). In experiment 2, H 111 was significantly different $(P=0.05)$ from the remaining selections; however, WI 352 was not significantly different from $\mathrm{P} 30, \mathrm{P}$ 312, and P 327.

Histological examination of seedlings from $\mathrm{H} 111$ and WI 352 seed sources showed that extensive colonization in needles was unrestricted by host responses and corresponded well with early onset of seedling mortality. Secondary needles of seedlings from susceptible selections $\mathrm{H}$ 111 and WI 352 exhibited many large, yellow-green, mottled spots. One microscopic feature common in infected needles of both susceptible selections (H 111 and WI 352), but found less frequently among spots of seedlings representing other selections, was a large area of densely packed mycelium located around the vascular bundle (Fig. 1A). This is similar to Clinton and McCormick's (3) early description of infected eastern white pine needles. Hyphae of $C$. ribicola were present throughout intercellular spaces, and haustoria were seen in mesophyll and transfusion cells as well as vascular elements (Fig. 1A). The cytoplasm of some mesophyll cells in which haustoria had developed was intact but had a granulated appearance, whereas in other areas, the mesophyll cells had collapsed, and no cellular contents were apparent. However, transfusion cells located around the vascular bundle did not display significant cytoplasmic and organelle disruption after haustorial development and were often completely filled with hyphae. Hyphae were much less abundant in infected vascular tissue, but the individual hyphae observed had usually produced haustoria. When phloroglucinol was used to stain sections that exhibited this type of interaction, no red coloration was observed, indicating the relative absence of polyphenolics. Similar responses to infection were observed in some needles from seedlings of even resistant seed sources tested in this study, as responses appeared to vary within and among seedlings of a single seed source.

Another type of interaction identified in needles from the susceptible selections WI 352 and H 111 was indicated by a macroscopic spot that was dull yellow or mottled in appearance but smaller than the previous example. When examined microscopically (Fig. 1B), the region of mycelia around the vascular bundle was smaller and more densely packed than in the previously described reaction. However, individual hyphae radiated from the central region of disruption and were present throughout intercellular spaces, infecting both mesophyll and transfusion cells. Hyphae and haustoria were also present in vascular tissue. C. ribicola had actually colonized a greater proportion of the entire needle in this type of reaction than in the previously described type. No staining was evident after sections were treated with phloroglucinol, indicating a lack of polyphenolic compounds in response to infection similar to the previously described "susceptible" interaction.

A pattern of needle tissue colonization and host response common to seedlings of family P 30 is shown in Figures $2 \mathrm{~A}$ and B, which are micrographs of the same area of an infected needle stained with periodic acid-Schiff's reagent and phloroglucinol$\mathrm{HCl}$, respectively. In Figure 2A, a confined area of hyphae is indicated by the magenta color located around the vascular bundle after staining with periodic acid-Schiff's

Table 1. Time (weeks) for seedlings from five eastern white pine families inoculated with Cronartium ribicola to reach 30,50 , and $70 \%$ mortality in two experiments

\begin{tabular}{lccccccc}
\hline & \multicolumn{3}{c}{ Experiment 1 } & & \multicolumn{3}{c}{ Experiment 2 } \\
\cline { 2 - 4 } \cline { 7 - 8 } Family & $\mathbf{3 0 \% ^ { \mathbf { z } }}$ & $\mathbf{5 0 \%}$ & $\mathbf{7 0 \%}$ & & $\mathbf{3 0 \%}$ & $\mathbf{5 0 \%}$ & $\mathbf{7 0 \%}$ \\
\hline H 111 & $24 \mathrm{a}$ & $28 \mathrm{a}$ & $30 \mathrm{a}$ & & $10 \mathrm{a}$ & $10 \mathrm{a}$ & $12 \mathrm{a}$ \\
WI 352 & $24 \mathrm{a}$ & $26 \mathrm{a}$ & $34 \mathrm{a}$ & & $12 \mathrm{~b}$ & $14 \mathrm{~b}$ & $21 \mathrm{~b}$ \\
P 30 & $38 \mathrm{~b}$ & $54 \mathrm{~b}$ & $64 \mathrm{~b}$ & & $14 \mathrm{~b}$ & $22 \mathrm{~b}$ & $40 \mathrm{~b}$ \\
P 312 & $34 \mathrm{~b}$ & $46 \mathrm{~b}$ & $58 \mathrm{~b}$ & & $14 \mathrm{~b}$ & $20 \mathrm{~b}$ & $38 \mathrm{~b}$ \\
P 327 & $34 \mathrm{~b}$ & $60 \mathrm{~b}$ & $150 \mathrm{~b}$ & & $12 \mathrm{~b}$ & $20 \mathrm{~b}$ & $40 \mathrm{~b}$ \\
\hline
\end{tabular}

${ }_{\mathrm{z}}$ Values within a column followed by the same letter are not significantly different $(P=0.05)$ based on the Kaplan-Meier analysis, preformed with the assistance of Statistix ${ }^{\circledR 7}$ software. 
reagent. The colonization was restricted and polyphenolic compounds were detected around the infection site, as indicated by a reddish-pink color after staining with phloroglucinol-HCl (Fig. 2B). Sparse hyphae were observed in the intercellular spaces surrounding the localized mycelial mass. These hyphae appeared shrunken and distorted and did not appear to have produced haustoria in mesophyll, transfu-
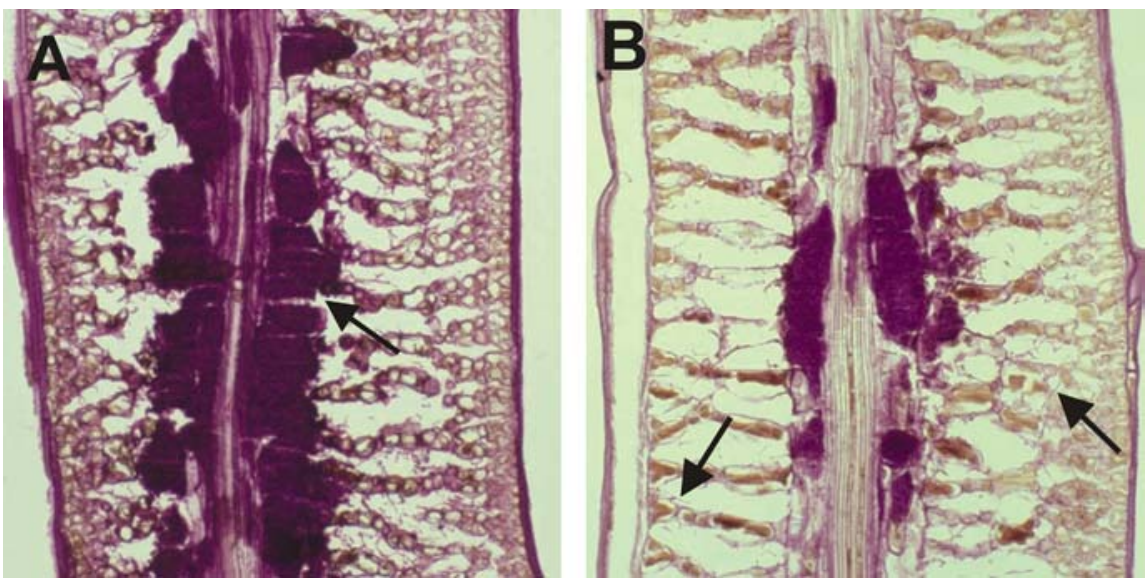

Fig. 1. Micrographs of infected eastern white pine secondary needles 7 weeks after inoculation, stained with periodic acid-Schiff's reagent, from seedlings of selections found to be susceptible to Cronartium ribicola. A, Selection WI 352 with arrows indicating a large area of densely packed, magenta-stained mycelium located around the vascular bundle. B, Arrows show individual hyphae radiating from a relatively small mycelial mass surrounding the vascular cylinder in selection $\mathrm{H} 111$.

sion, or vascular cells. Despite the presence of polyphenolic compounds indicative of a defense response for this type of interaction, the macroscopic appearance of such infections was a relatively large, yellow needle spot. However, such spots appeared to be a more intense yellow than needle spots typical of "fully susceptible" interactions.

A different interaction was observed in needles of selection P 312, in which the bright yellow spots were slightly swollen in appearance. Histological features of the reaction are illustrated in Figures $2 \mathrm{C}$ and D. In this type of interaction, needles produced abundant, abnormally large cells at the infection site and copious amounts of compounds that occluded cells (Fig. 2C). After phloroglucinol- $\mathrm{HCl}$ staining, the area surrounding the hypertrophic and hyperplasic cells stained a brilliant red, indicating high concentrations of polyphenolic compounds (Fig. 2D). This reaction appeared to delimit the growth of the fungus. A final type of response was observed in needles from selection $\mathrm{P} 327$, which had small, bright yellow spots when viewed macroscopically. The histological appear-
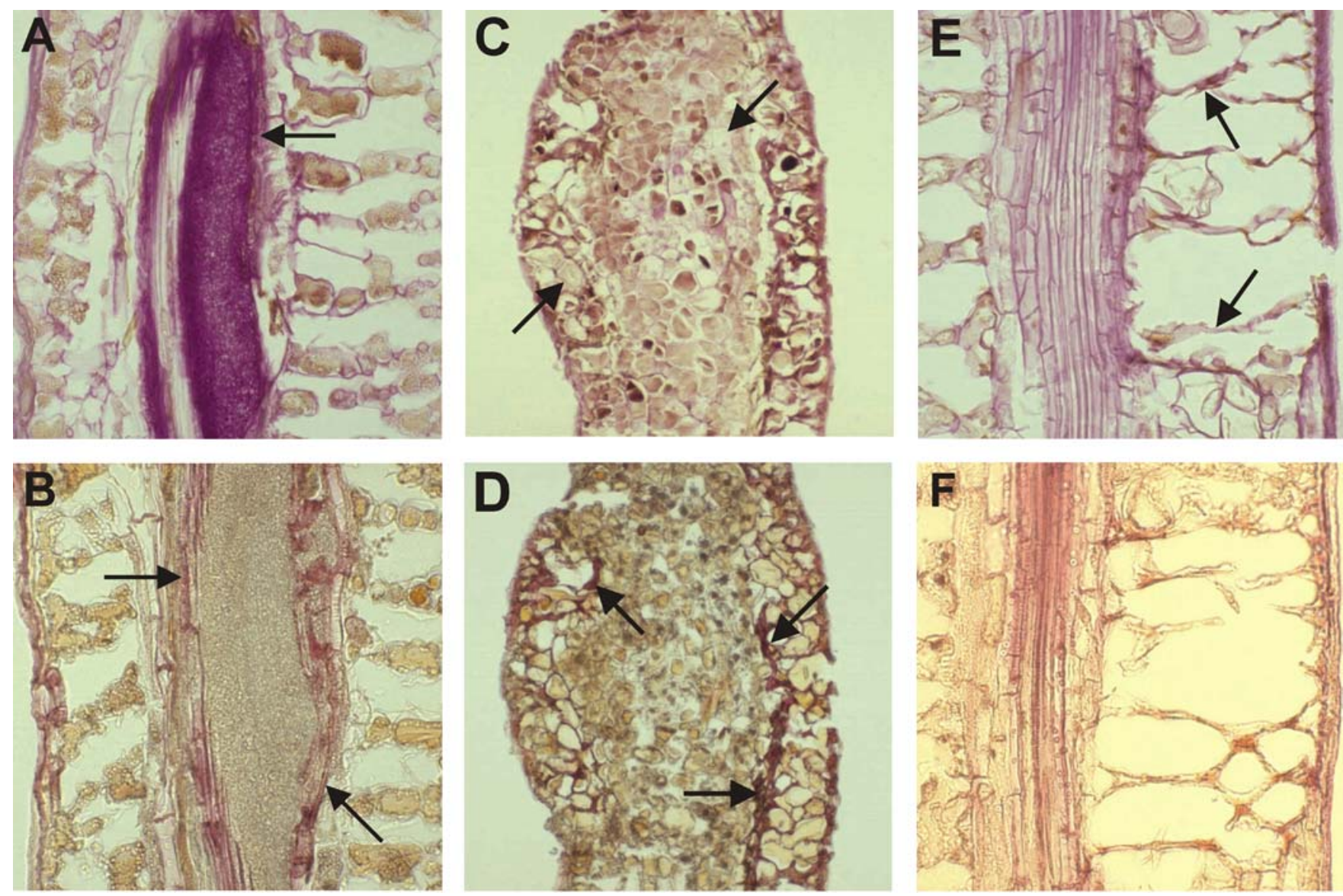

Fig. 2. A to F. Sections of secondary needles from three eastern white pine selections that appear to slow or inhibit white pine blister rust growth 7 weeks after inoculation. A, A confined area of infection in a needle from selection P 30 is indicated by magenta-stained mycelium around the vascular bundle (arrow) after staining with periodic acid-Schiff's reagent. B, Needle from selection P 30 seedling with highly localized infection (arrows). The section was stained for the presence of polyphenolics using phloroglucinol-HCl. C, Seedlings of resistant selection P 312 with abundant, abnormal cells (arrows) in needles. This section was stained with periodic acid-Schiff's reagent. D, Intense polyphenolic production (arrows) in needle from a P 312 seedling shows a positive reaction with phloroglucinol- $\mathrm{HCl}$ associated with hypertrophic and hyperplastic cells. E, Collapsed mesophyll cells in needle from resistant selection P 327. F, Little reaction to staining with phloroglucinol-HCl in a needle section of P 327, indicating limited production of polyphenolic compounds. 
ance of needles that exhibited this reaction was that of collapsed mesophyll (Fig. 2E) cells and an absence of phenolic compounds (Figs. 2F). The cells and transfusion tissue in close proximity to the infection were necrotic, although vascular elements remained unaltered.

\section{DISCUSSION}

Artificial inoculation of seedlings from open-pollinated $P$. strobus selections has demonstrated the potential importance of selecting trees that show reduced or delayed mortality and are able to slow or abort tissue colonization by $C$. ribicola. Dramatic differences in the ability to survive infection were observed for seedlings of different selections. When the two inoculation experiments were compared, the most pronounced differences were seen in the number of weeks required for populations of seedlings from resistant and susceptible selections to reach $70 \%$ mortality. Seedlings from selection P 327 exhibited the greatest capacity for survival after inoculation and required 150 weeks before reaching $70 \%$ mortality in experiment 1 . In contrast to seedlings from the susceptible selection H 111, seedlings from P 327 required five times as long to reach the same level of mortality despite the highly favorable conditions for infection and colonization. Seedlings from selections $\mathrm{P} 30$ and $\mathrm{P}$ 312 also showed a greater capacity for survival than those of family $\mathrm{H} 111$. When seedlings of these families are exposed to lower levels of inoculum under more natural growing conditions, they should be expected to have even greater survival compared with susceptible seedlings.

In experiment 2 , a few individuals from WI 352 survived the entire experiment and appeared to have escaped initial infection. WI 352 reached $70 \%$ mortality approximately 19 weeks sooner, or in half the time, than the more resistant selections, but because several seedlings remained free of infection, the percent mortality was not significantly different $(P=0.05)$ from $\mathrm{P}$ 30, P 312, and P 327.

When comparing mortality rates of inoculated H 111 and WI 352 seedlings to inoculated seedlings from general bulk seed of eastern white pine commonly used in Wisconsin DNR nurseries, the latter seedlings had greater amounts of infection and died more rapidly (J. A. Jurgens, R. A. Blanchette, P. J. Zambino, and A. David, unpublished data). This indicates that the open pollinated seed of even susceptible families H 111 and WI 352 appear to have a greater level of resistance than seedlings from bulk seed commonly used for seedling production.

The interactions observed in sections of needle tissue from seedlings of susceptible selections H 111 and WI 352 were very similar to what has been described in previous microscopic investigations in which mycelial aggregations in infected needles were described as "pseudosclerotia" or sclerotia-like masses $(7,20)$. In our studies with the two susceptible families, the fungus appeared to colonize host tissues unchecked by host reactions. Seedlings were killed in a much shorter period of time than those from the more resistant selections.

Selection P 30 had been observed previously $(8,18,20)$ to have some resistance to white pine blister rust. Those authors believed that the factors responsible for resistance in this family operated in inner bark tissue, since they observed substomatal vesicle development of the fungus in needles but no cankers on the main stems. Our histological investigation of this family supports previous suggestions by Patton and others $(18,20)$ that selection P 30 does exhibit resistance. However, it is possible that several different resistance mechanisms may be functioning within this selection (in bark and in needles), or that a single mechanism may have effectiveness in different tissues. The reduced amounts of colonizing mycelium and intense reaction when stained with phloroglucinol- $\mathrm{HCl}$ suggest that the polyphenolic compounds produced by the host may have a detrimental effect on the invading pathogen within needles.

The presence of polyphenolic compounds during MGR-resistant reactions of sugar pine to blister rust has been previously described by Kinloch and Littlefield (14). They noted that mycelium appeared to be confined by dense, dark-brown deposits, which they assumed to be tannins. Polyphenolic compounds deposited in cell walls have been implicated as a crucial resistant element in other disease systems, and inducible levels of polyphenolic compounds in even race-specific systems can have quantitative inheritance (27). More recently, the inhibitory effects of phenolic compounds derived from red pine (P. resinosa) on mycelium of Sphaeropsis sapinea were discussed by Blodgett and Stanosz (1).

Pathogens can cause an imbalance in hormones produced by the host and create abnormal growth responses that are incompatible with the healthy development of the plant (5). This is one explanation for the limited hypertrophy and hyperplasia occurring in needles of seedlings from selection P 312. The hypertrophic and hyperplastic reactions in conjunction with the copious amounts of polyphenolic compounds identified in needles may contribute to the arrest of fungal colonization in $\mathrm{P}$ 312.

Seedlings of P 327 had the highest level of resistance. More than three decades ago, Patton (18) and Patton and Johnson (20) referred to this selection as highly resistant because many of its progeny lacked substomatal vesicle production. In the needles examined in our study, an intense host reaction to infection occurred and cells were killed around the infection site. This intense response appears similar to a hypersensitive reaction that reduces the available cells for the obligate parasite to colonize. The dead cells may create a physical barrier that inhibits subsequent colonization and reduces nutrient availability for $C$. ribicola. A variety of resistance mechanisms could be operating in these different selections of white pine, and reactions in the needles as well as the stems may be responsible for reduced rates of disease incidence.

Further investigation is needed to determine the details of host resistance mechanisms observed in eastern white pine. Recently, controlled pollination studies have been made between various resistant and nonresistant selections using a full diallel mating scheme to generate seedlings of known lineage. Seedlings from these controlled crosses will be used in future inoculations and histological investigations.

The investigations reported here provide an important step in the understanding of the mechanisms responsible for resistant reactions in needles of eastern white pine after inoculation with $C$. ribicola. The results will be of use to help select additional eastern white pine families for breeding programs and to produce white pine blister rust-resistant trees to meet horticultural, timber, aesthetic, and ecological restoration objectives.

\section{ACKNOWLEDGMENTS}

This research was supported by funds from the Minnesota Department of Natural Resources. Special thanks to Robert Stine for his efforts to obtain the funding used in this study and Bill Sery and the staff at the Oconto River Seed Orchard for white pine seed. We also thank Emeritus Professor Robert Patton, University of Wisconsin, for reviewing the manuscript and providing helpful suggestions, Yu-Min Huang for assistance with statistical analysis, and Jason Smith and Todd Burnes for their helpful discussions and suggestion.

\section{LITERATURE CITED}

1. Blodgett, J. T., and Stanosz, G. R. 1997 Differential inhibition of Sphaeropsis sapinea morphotypes by a phenolic compound and several monoterpenes of red pine. Phytopathology 87:606-609.

2. Boyer, M. G., and Isaac, P. K. 1964. Some observations on white pine blister rust as compared by light and electron microscopy. Can J. Bot. 42:1305-1309.

3. Clinton, G. P., and McCormick, F. A. 1919 Infection experiments of Pinus strobus with Cronartium ribicola. Pages 428-459 in: Report of the Botanist for Years 1917-1918. Conn. Agric. Exp. Stn. Bull. 214.

4. Dring, D. M. 1955. A periodic acid-Schiff technique for staining fungi in higher plants. New Phytol. 54:277-279.

5. Hahlbrock, K., and Scheel, D. 1989. Physiology and molecular biology of phenylpropanoid metabolism. Annu. Rev. Plant Physiol Plant Mol. Biol. 40:347-369.

6. Hirt, R. R. 1939. Canker development by Cronartium ribicola on young Pinus strobus. Phytopathology 29:1067-1076.

7. Hoff, R. J., and McDonald, G. I. 1971. Resistance to Cronartium ribicola in Pinus monticola: Short shoot fungicidal reaction. Can. J. Bot. 49:1235-1239. 
8. Hunt, R. S., and Meagher, M. D. 1989. Incidence of blister rust on "resistant" white pine (Pinus monticola and Pinus strobus) in coastal British Columbia plantations. Can. J. Plant Pathol. 11:419-423.

9. Johansen, D. A. 1940. Plant microtechnique. McGraw-Hill Book Co., New York.

10. Kaplan, E. L., and Meier, P. 1958. Nonparametric estimation from incomplete observations. J. Am. Stat. Assoc. 53:457-481.

11. Kinloch, B. B., Jr. 1980. Effect of photoperiod and container size on sugar pine seedling growth and infection by white pine blister rust. 1-4. Research Notes PSW-343. USDA Forest Service, Pacific Southwest Forest and Range Experiment Station, Berkeley, CA.

12. Kinloch, B. B, Jr., and Davis, D. 1996. Mechanisms and inheritance of resistance to blister rust in sugar pine. Pages 125-132 in: Sugar Pine: Status, Values, and Roles in Ecosystems. B.B. Kinloch, Jr., M. Marosy, and M. E. Huddleston, eds. Proc. Sympos. presented by Calif. Sugar Pine Manage. Comm. University of California, Div. Agric. Nat. Res., Davis, CA. Publ. 3362

13. Kinloch, B. B., Jr., and Dupper, G. E. 2002. Genetic specificity in the white pine-blister rust pathosystem. Phytopathology 92:278280.

14. Kinloch, B. B., Jr., and Littlefield, J. L. 1977. White pine blister rust: Hypersensitive resistance in sugar pine. Can. J. Bot. 55:1148-1155.

15. Kinloch, B. B., Jr., Sniezko, R. A., Barnes, G.
D., and Greathouse, T. E. 1999. A major gene for resistance to white pine blister rust in western white pine from the Western Cascade Range. Phytopathology 89:861-867.

16. Krebill, R. G. 1968. Histology of canker rusts in pines. Phytopathology 58:155-164.

17. Maloy, O. C. 2001. White pine blister rust. Plant Health Progress. Online, doi: 10.1094/PHP-2001-0924-01-HM

18. Patton, R. F. 1967. Factors in white pine blister rust resistance. Pages 876-890 in: Proc. XIVth Iufro Congr., Sept. 4-9, 1967, Munich, Germany. Part III, Section 22 and Intersectional Working Group 22/24.

19. Patton, R. F. 1972. A brief conspectus of pathology and genetics of Cronartium ribicola as related to resistance. Pages 431-444 in: Biology of rust resistance in forest trees. R. T. Bingham, R. J. Hoff, and G. I. McDonald, eds. Proc. NATO-IUFRO Advanced Study Institute, Aug. 17-24, 1969. USDA Misc. Pub. No. 1221.

20. Patton, R. F., and Johnson, D. W. 1970. Mode of penetration of needles of eastern white pine by Cronartium ribicola. Phytopathology 60:977-982.

21. Patton, R. F., and Riker, A. J. 1966. Lessons from nursery and field testing of eastern white pine selections and progenies for resistance to blister rust. Pages 403-420 in: Breeding PestResistant Trees. H. D. Gerhold et al., eds. Proc. N.A.T.O. and N.S.F. Sympos. held at The Pennsylvania State University, Aug. 30 to
Sept. 11, 1964. Pergamon Press, New York.

22. Patton, R. F., and Spear, R. N. 1980. Stomata influence on white pine blister rust infection. Phytopathol. Mediterr. 19:1-7.

23. Riker, A. J., Kouba, T. F., and Brener, W. H. 1949. Selecting white pine for resistance to blister rust. (Abstr.) Phytopathology 39:20.

24. Riker, A. J., Kouba, T. F., Brener, W. H., and Patton, R. F. 1953. White-pine trees selected for resistance to white-pine blister rust. Proc. Int. Bot. Congr., 7th, Stockholm, Sweden, 1950. 14:48.

25. Struckmeyer, E. B., and Riker, A. J. 1951 Wound-periderm formation in white pine trees resistant to blister rust. Phytopathology 41:276-281.

26. Van Arsdel, E. P. 1968. Stem and needle inoculations of eastern white pine with the blister rust fungus. Phytopathology 58:512 514.

27. Vance, C. P., Kirk, T. K., and Sherwood, R. T. 1980. Lignification as a mechanism of disease resistance. Annu. Rev. Phytopathol. 18:259288.

28. Woo, K.-S., Fins, L., McDonald, G. I., and Wiese, M. V. 2001. Differences in needle morphology between blister rust resistant and susceptible western white pine stocks. Can. J. For. Res. 31:1880-1886.

29. Zambino, P. J., and Michler, C. H. 1999 Accelerated identification of eastern white pine families resistant to white pine blister rust. (Abstr.) Phytopathology 89:S89. 